\title{
Determination of Total Iodine Concentration in Aquatic Environments Using Cathodic Stripping Voltammetry Combined with Sodium Hypochlorite (NaClO) Oxidation
}

\author{
Yuhi SATOH, Shigeyoshi OTOSAKA, Takashi SUZUKI \\ Research Group for Environmental Science, Japan Atomic Energy Agency (JAEA), 2-4 \\ Shirakata-Shirane, Tokai, Ibaraki 319-1195, Japan

\begin{abstract}
An easy and fast method for the determination of total iodine in environmental samples by cathodic stripping voltammetry combined with sodium-hydrochlorous-induced oxidation ( $\mathrm{NaClO}$ oxidation) has been developed. Adequate conditions for $\mathrm{NaClO}$ oxidation of $40-50^{\circ} \mathrm{C}$ over $2 \mathrm{~h}$ were determined, using three representative environmental samples (reference soil, seabed sediment, seaweed). By analyzing a mixture of thyroxin and a reference soil material, an overall recovery of $>97 \%$ for total iodine in the concentration range of $1-7 \mu \mathrm{mol} / \mathrm{g}$ was obtained. This method was compared with alkaline extraction and combustion methods for solid (reference soil, seabed sediments, seaweed, and filter) and aqueous environmental samples. Alkaline extraction exhibited lower recovery of iodine compared with the $\mathrm{NaClO}$ oxidation method, indicating insufficient extraction and/or interference on determination. Combustion method also showed lower iodine recovery for some samples, probably due to a trapping efficiency and incomplete combustion of organic matter.
\end{abstract}

Keywords: cathodic stripping voltammetry, $\mathrm{NaClO}$ oxidation, total iodine

\section{INTRODUCTION}

Iodine is known as a biophilic element. Despite its thermodynamic stability, environmental iodine is readily transferred to organic iodine (organo-iodine: OI) and iodate (e.g., Elderfield and Truesdale, 1980; Luther III et al., 1991). Although many studies have shown that the transformation is facilitated by both biotic and abiotic factors (Harvey, 1980; Wong, 1982; Amachi, 2008), thermodynamic details of environmental iodine transfer are not well understood.

In an aquatic environment, particulate materials, such as biogenic/lithogenic suspended particles, biota, and sediment, can be separated from dissolved materials by filtration through a filter with a $0.1-0.7 \mu \mathrm{m}$ pore size (Hedges, 2002).

In such particulates, iodine is mainly incorporated into organic matter (Harvey, 1980; Wong, 1982; Francois, 1987). Typically, neutron activation analysis (NAA) (Becker et al., 1972; Hou et al., 1997) or X-ray fluorescence analysis (XRF) (Elderfield and Truesdale, 1980; Harvey, 1980; Kupper et al., 2008) are used to determine the concentration of iodine in particulate materials such as sediments, seaweeds, and plankton. These methods permit direct measurement of total iodine without dissolution/decomposition of the solid samples. However, NAA requires an expensive equipment and complex preparation, and XRF is not applicable for samples with small amount or low concentration of iodine (detection limit: $\geq 24 \mathrm{nmol}, \geq 63 \mathrm{nmol} / \mathrm{g}$ (Harada and Sakurai, 1999).

Address correspondence to Yuhi Satoh, Research Group for Environmental Science, Japan Atomic Energy Agency (JAEA), Email: sato.yuhi@jaea.go.jp

Received September 21, 2013, Accepted December 2, 2013 
Dissolved iodine has been determined by several methods, such as absorbance (Truesdale and Spencer, 1974), inductively coupled plasma-mass spectrometry (ICP-MS) (Chen et al., 2007), and gas chromatography-mass spectrometry (GC-MS) (Zhang et al., 2010). In these methods, cathodic stripping voltammetry exhibits a remarkable ability in determining low concentrations of iodine (detection limit of total inorganic iodine: $\geq 0.2 \mathrm{nmol} / \mathrm{L}$ ) (Campos, 1997), and can be applied to trace the behavior of iodine in aquatic environments in detail.

Although most of these methods can also be applied to measuring the different iodine species: iodide $\left(\mathrm{I}^{-}\right)$, iodate $\left(\mathrm{IO}_{3}{ }^{-}\right)$, and OI, it is difficult to measure concentrations of dissolved OI (DOI) directly. In such a case, OI concentration is estimated as a deficit of iodate from the total amount of iodine. In order to measure the concentration of the total iodine in aqueous samples, it is necessary to remineralize OI into inorganic iodine (i.e., iodide or iodate) by combustion or chemical degradation. In a conventional dry combustion procedure, an aqueous sample is heated in a furnace at $900-1000^{\circ} \mathrm{C}$ under an oxidation catalyst (Muramatsu et al., 2008; Zhang et al., 2010). This method converts $92.7 \%$ of the OI into inorganic iodine (Zhang et al., 2010). Ultraviolet (UV) irradiation also has been applied to the combustion OI in aqueous samples (Wong and Chen, 1998), and has been shown to enhance OI conversion significantly. However, if there is a certain amount of DOI in a sample, these methods sometimes underestimate the concentration of total iodine $\left(\mathrm{I}^{-}+\mathrm{IO}_{3}{ }^{-}+\mathrm{OI}\right)$ in the sample. Alternatively, OI can also be chemically converted by hypochlorite $(\mathrm{NaClO})$ or other basic regents. Alkaline conversion has generally been used in sample preparation in geochemical analyses (Chao and Sanzolone, 1992), and has also been applied to iodine analysis (Hou et al., 2009). However, previous studies pointed out that soils and sediments contain a certain amount of alkaline-insoluble organic matter; this leads to lowered efficiency of remineralization of OI (e.g., Stevenson and Goh, 1971; Ertel and Hedges, 1984; Schnitzer and Schuppli, 1989). Oxidation by $\mathrm{NaClO}$ converting DOI into inorganic iodine, is operationally convenient because it can process multiple samples simultaneously (Takayanagi and Wong, 1986; Luther III et al., 1991; Wong and Chen, 1998; Cook et al., 2000). Since conversion by wet chemistry is sensitive to ionic strength, temperature, and reaction time (Chao and Sanzolone, 1992; McKenna and Doering, 1995), it is necessary to set a moderate base condition for the environment sample. It has been reported that the $\mathrm{NaClO}$ oxidation may underestimate DOI (Takayanagi and Wong, 1986; Wong and Chen, 1998), suggesting that the $\mathrm{NaClO}$ method needs further modification.

In the present study, the method of combining, adequate conditions of the $\mathrm{NaClO}$ oxidation, with measurement by cathodic stripping voltammetry, for determining the amount of iodine in environmental samples is evaluated. This method has been applied to measuring the total iodine in several representative samples, as well as being validated by comparison with conventional methods.

\section{MATERIALS AND METHODS}

\section{Samples}

Details of samples are listed in Tables 1 and 2. Thyroxin (Wako Pure Chemical Industries, Ltd., Osaka, Japan) and reference soils (NCS DC 73320, GBW 07402), from 
the China National Analysis Center, were selected. To decide an applicable range of concentration, a selection of samples with a range of known concentrations was prepared. Test samples were made as follows: reference soil $(220-230 \mathrm{mg})$ and thyroxin $(48-334 \mu \mathrm{g}$, thyroxin-iodine: $247.1-1,719.7 \mathrm{nmol})$ were put in a polypropylene (PP) centrifuge tube $(15 \mathrm{~mL})$. Theoretical concentration of thyroxin-iodine in the test samples was $1,065.2-7,337.6 \mathrm{nmol} / \mathrm{g}$.

Table 1 - Samples used in the experiment.

\begin{tabular}{|c|c|c|}
\hline \multicolumn{3}{|c|}{ Reference samples } \\
\hline $\begin{array}{l}\text { Thyroxin } \\
\left(\mathrm{C}_{15} \mathrm{H}_{11} \mathrm{I}_{4} \mathrm{NO}_{4}\right)\end{array}$ & \multicolumn{2}{|c|}{ Purchased from Wako Pure Chemical Industries, Ltd., Osaka, Japan } \\
\hline Reference soil & \multicolumn{2}{|c|}{$\begin{array}{l}\text { NCS DC } 73320 \text { (GBW 07402) soil, provided by China National } \\
\text { Analysis Center }\end{array}$} \\
\hline \multicolumn{3}{|c|}{ Environmental samples } \\
\hline Seabed sediment & Sampling site & Sampling date \\
\hline A & Hitachi off (N36.46, E140.54) & May/08/2013 \\
\hline $\mathrm{B}$ & Fukushima off (N37.19, E142.12) & Oct $/ 29 / 2011$ \\
\hline \multicolumn{3}{|l|}{ Seaweed } \\
\hline Ulva & Kuji River estuary (N36.29, E140.37) & Jun/10/2013 \\
\hline \multicolumn{3}{|l|}{ Water } \\
\hline A & Kuji River estuary (N36.29, E140.37) & $\mathrm{Jul} / 08 / 2013$ \\
\hline $\mathrm{B}$ & Tokyo Bay (N35.45, E139.66) & $\mathrm{Jul} / 08 / 2013$ \\
\hline
\end{tabular}

Table 2 - General data of samples.

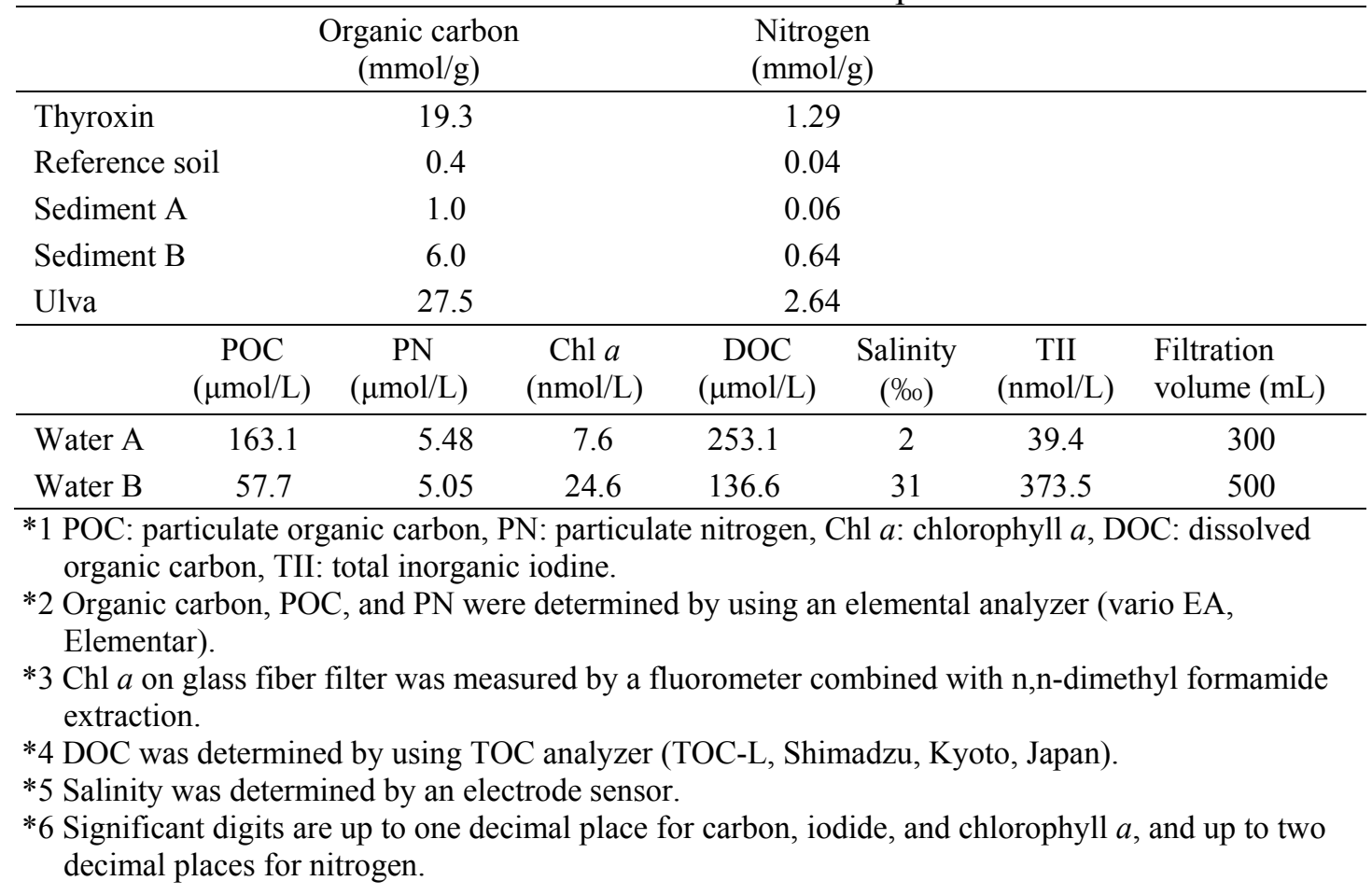


For environmental samples, two kinds of seabed sediments, seaweed (ulva), and two kinds of natural waters were prepared.

Natural water samples were filtrated through a preheated $\left(500^{\circ} \mathrm{C}, 5 \mathrm{~h}\right)$ glass fiber filter (GF/F, Whatman, Buckinghamshire, England), and both the filter and filtrate were used in the experiment. During filtration, dissolved iodine absorbed by the filter was removed with iodine-free brine water $(30 \mathrm{~g} \mathrm{NaCl} / \mathrm{L})$. The filtrate samples were stored at $-20^{\circ} \mathrm{C}$ until the experiments were prepared.

Sediments, seaweed, and filter samples were dried for $24 \mathrm{~h}$ at $60^{\circ} \mathrm{C}$, and were used for the experiments.

\section{Decomposition of organo-iodine}

\section{$\mathrm{NaClO}$ oxidation}

An aqueous solution of $\mathrm{NaClO}$ (Wako Pure Chemical Industries, Ltd), of which chlorine concentration was determined preliminarily by a residual chlorine analyzer (HI711, Hanna, Chiba, Japan), was diluted by ultra-pure water $(\geq 18.2 \mathrm{M} \Omega$ ), to a final concentration of $0.3 \%$ of $\mathrm{NaClO}(\mathrm{w} / \mathrm{w})$. An aliquot of reference soil (ca. $20 \mathrm{mg}$ ), seaweed (ca. $10 \mathrm{mg}$ ), or thyroxin $(134-624 \mu \mathrm{g}$, thyroxin-iodine: $690-3,190 \mathrm{nmol})$ was transferred to a PP centrifuge tube $(15 \mathrm{~mL})$ and $\mathrm{NaClO}(0.3 \%, 1-3 \mathrm{~mL})$ solution was added. Samples were placed in an ultrasonic bath $(40 \mathrm{kHz}, 80 \mathrm{~W})$ for $1-6 \mathrm{~h}$, followed by the addition of $0.1 \mathrm{~mol} / \mathrm{L}$ ascorbic acid (Wako Pure Chemical Industries, Ltd) to terminate oxidation. The reaction mixtures were filtered through a cellulose membrane syringe filter $(0.45 \mu \mathrm{m}$ pore size, Advantec, Tokyo, Japan), and the filtrates were stored at $4^{\circ} \mathrm{C}$ until the analysis.

Filtered natural water $(4.5 \mathrm{~mL})$ was transferred into a PP centrifuge tube $(15 \mathrm{~mL})$ and subsequently, $\mathrm{NaClO}(3 \%, 0.5 \mathrm{~mL})$ was added, followed by the oxidation procedure described above. Ascorbic acid solution $(0.5 \mathrm{~mol} / \mathrm{L}, 1 \mathrm{~mL})$ was added to terminate the oxidation. The reaction mixture was stored at $4^{\circ} \mathrm{C}$ until analyzed.

\section{Dry combustion}

The dry combustion procedure was carried out after the method of Zhang et al. (2010). An aliquot of reference soil (ca. $20 \mathrm{mg}$ ), sediments (ca. $20 \mathrm{mg}$ ), or seaweed (ca. $10 \mathrm{mg}$ ) was placed in a quartz boat with vanadium pentoxide catalyst (ca. $20 \mathrm{mg}$ ) (Wako Pure Chemical Industries, Ltd). For filtered natural waters, an aliquot (c.a. $3 \mathrm{~mL}$ ) of sample was transferred into a quartz boat with vanadium pentoxide (ca. $20 \mathrm{mg}$ ).

The quartz boat, with sample inside, was placed in a combustion tube connected to a trap containing $3 \mathrm{~mL}$ of ultrapure water and heated under moist oxygen gas (150 $\mathrm{mL} / \mathrm{min}$ ). The temperature program was $200^{\circ} \mathrm{C} 15 \mathrm{~min}, 900^{\circ} \mathrm{C}$ for c.a. $20 \mathrm{~min}$, after which the furnace was turned off. When the temperature decreased to $700^{\circ} \mathrm{C}$, the water trap was taken from the combustion tube and the collected water was stored at $4^{\circ} \mathrm{C}$ until the analysis.

\section{Alkaline degradation}

Following Schnitzer and Schuppli (1989), $\mathrm{NaOH}$ was used as an alkaline reagent. An aliquot of reference soil (ca. $20 \mathrm{mg}$ ), sediments (ca. $20 \mathrm{mg}$ ), or seaweed (ca. $10 \mathrm{mg}$ ) was 
transferred into a PP centrifuge tube $(15 \mathrm{~mL})$ and, $1 \mathrm{~mL}$ of aqueous solution of $\mathrm{NaOH}(3$ $\mathrm{mol} / \mathrm{L}$ ) (Polysciences, Pennsylvania, USA) was added. The conditions of the reaction were the same as for the $\mathrm{NaClO}$ oxidation. At the end of the reaction, $1 \mathrm{~mL}$ of aqueous solution of boracic acid $(0.5 \mathrm{~mol} / \mathrm{L})$ (Wako Pure Chemical Industries, Ltd) was added, followed by the addition of $1 \mathrm{~mL}$ of $3 \mathrm{~mol} / \mathrm{L} \mathrm{HCl}$ (Wako Pure Chemical Industries, Ltd) and $1 \mathrm{~mL}$ of $0.1 \mathrm{~mol} / \mathrm{L}$ ascorbic acid. The reaction mixture was filtered by the same procedure in section of ' $\mathrm{NaClO}$ oxidation' and the collected filtrate was stored at $4^{\circ} \mathrm{C}$ until analyzed.

\section{Measurement of iodine}

The iodine concentration of the aqueous sample was measured by cathodic stripping voltammetry. The details of the procedure have been reported by Campos (1997). An arbitrary amount of sample solution (around $10 \mathrm{~mL}$ ) was transferred to a voltammetric cell with $0.5 \mathrm{~mL}$ of ascorbic acid $(0.1 \mathrm{nmol} / \mathrm{L})$ and $0.5 \mathrm{~mL}$ of $\mathrm{HCl}(1 \mathrm{~mol} / \mathrm{L})$ which reduce iodate to iodide. After the addition of $0.5 \mathrm{~mL}$ of ammonia $(1 \mathrm{~mol} / \mathrm{L}), 0.5 \mathrm{~mL}$ of borate buffer ( $1 \mathrm{~mol} / \mathrm{L})$ (Polysciences, Pennsylvania, USA), and $0.5 \mathrm{~mL}$ of Triton X-100 $(0.2 \%)$ (Wako Pure Chemical Industries, Ltd), the total iodine concentration detected as iodide was determined by a 797VA Computrace (Metrohm, Herisau, Switzerland) with a hanging mercury drop electrode. The analytical condition included the following parameters: purge gas, nitrogen; deposition potential, $0 \mathrm{~V}$; step potential, $2 \mathrm{mV}$; wave amplitude, $20 \mathrm{mV}$; frequency, $50 \mathrm{~Hz}$; quiescent time, $5 \mathrm{~s}$; and scanning range, 0 to -0.7 V.

\section{RESULTS AND DISCUSSION \\ Condition of $\mathrm{NaClO}$ oxidation}

The results of $\mathrm{NaClO}$ oxidation of reference soil, sediment $\mathrm{A}$, and seaweed are exhibited in Fig 1. The iodine concentration in the reaction mixture for reference soil (Fig 1A) showed a dependence on temperature conditions; concentrations obtained from reaction at $40-50^{\circ} \mathrm{C}$ were higher than those at $20-30^{\circ} \mathrm{C}$. At $40-50^{\circ} \mathrm{C}$, iodine concentrations were almost constant after $2 \mathrm{~h}$ (t-test, $\mathrm{p}>0.3$ ). Similar temperature dependence in iodine concentration was also shown for sediment A (Fig 1B). However, the results for seaweed (Fig 1C) showed no significant temperature dependence (t-test, $p$ $>0.3$ ). From these results, it was determined that adequate conditions for $\mathrm{NaClO}$ oxidation are $40-50^{\circ} \mathrm{C}$ for $2 \mathrm{~h}$. It can be considered that these determined conditions were applied to all samples used in this study.

It is known that volatile OI is produced by seaweed and phytoplankton in aquatic environments. Methyl iodide (boiling point: $42^{\circ} \mathrm{C}$ ) have been studied closely (Amachi, 2008). If there is a significant amount of volatile $\mathrm{OI}$ in samples, $\mathrm{NaClO}$ oxidation at 40 $-50^{\circ} \mathrm{C}$ may underestimate the total iodine. However, iodine concentration extracted from seaweed, which is a major producer of volatile OI in aquatic environments, showed no significant difference in OI concentration between $20-30^{\circ} \mathrm{C}$ and $40-50^{\circ} \mathrm{C}$ conditions. This result would indicate that the loss of volatile OI is insignificant in the present study.

In order to determine the efficiency of $\mathrm{NaClO}$ oxidation, the following conditions were applied to thyroxin, a natural compound of known OI content $(\mathrm{NaClO}$ concentration: 
$0.3 \%$, temperature: $40-50^{\circ} \mathrm{C}$, reaction time: $2 \mathrm{~h}$ ). Within the range from 690.0 to $3,192.3 \mathrm{nmol}$ of iodine, the results show approximate full recovery (Table 3 ). Wong and Chen (1998) have reported that an oxidation recovery of thyroxin-iodine using low concentration of $\mathrm{NaClO}(0.002-0.003 \%)$ was $46 \%$. This result suggests that recovery of OI depends on the concentration of $\mathrm{NaClO}$. The present study shows the improved condition for reaction efficiency. The recovery experiment using thyroxin combined with reference soil also resulted in sufficient recovery of total iodine (Fig 2). From these results we conclude that the present method guarantees sufficient extraction of iodine from environmental samples with the range of $\geq 3192.3 \mathrm{nmol}$, or $\geq 7337.6 \mathrm{nmol} / \mathrm{g}$ of iodine.

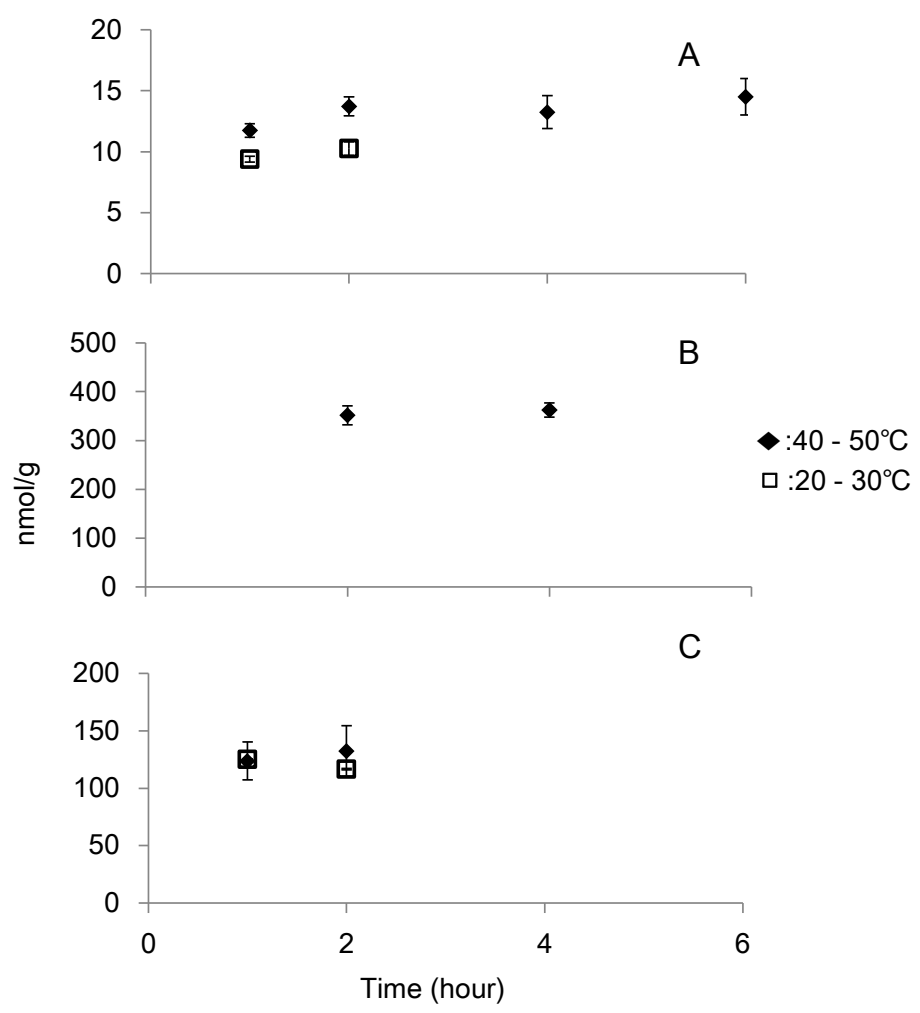

Fig. 1 - Time series of iodine concentration in reaction mixture extracted from (A) reference soil, (B) sediment A, and (C) seaweed. Error bars represent SD $(n=5)$.

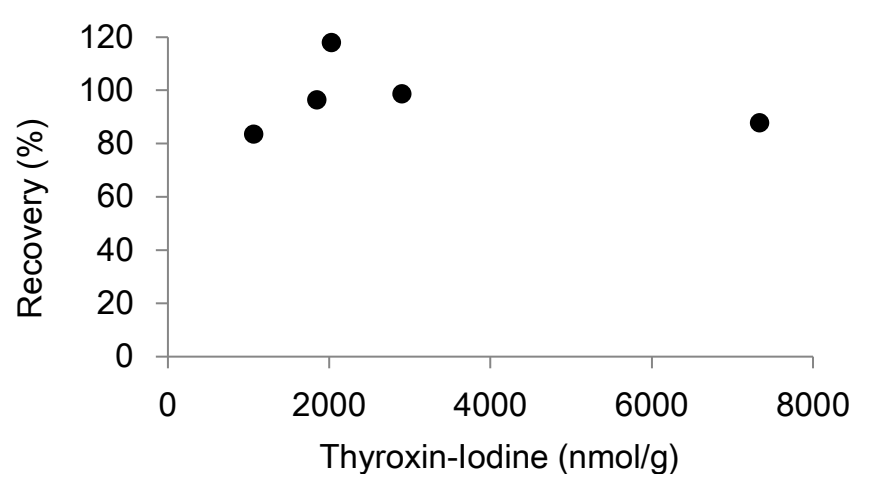

Fig. 2 - Recovery of total iodine in 5 samples, each with a different concentration of OI. The experiment was carried out using a mixture of thyroxin and reference soil. 
Table 3 - Results of total iodine determination by $\mathrm{NaClO}$ oxidation, $\mathrm{NaOH}$, and combustion.

\begin{tabular}{|c|c|c|c|}
\hline & $\mathrm{NaClO}$ & $\mathrm{NaOH}$ & Combustion \\
\hline \multirow{3}{*}{ Thyroxin $(134-620 \mu \mathrm{g})$} & Recovery (\%) & & \\
\hline & $103( \pm 15, \mathrm{n}=5)$ & & \\
\hline & \multicolumn{3}{|c|}{ Concentration (nmol/g) } \\
\hline Reference soil & $13.4( \pm 0.8, \mathrm{n}=5)$ & $8.6( \pm 2.0, n=5)$ & $18.5( \pm 3.8, \mathrm{n}=5)$ \\
\hline Sediment A & $351.5( \pm 19.7, \mathrm{n}=5)$ & $\begin{array}{l}259.3 \\
( \pm 30.7, \mathrm{n}=5)\end{array}$ & $345.9( \pm 15.8, \mathrm{n}=5)$ \\
\hline Sediment B & $\begin{array}{l}7013.3 \\
( \pm 355.9, \mathrm{n}=5)\end{array}$ & & $5264.5( \pm 180.3, \mathrm{n}=3)$ \\
\hline \multirow[t]{2}{*}{ Ulva } & $132.1( \pm 22.1, \mathrm{n}=5)$ & & $133.9( \pm 9.5, \mathrm{n}=5)$ \\
\hline & \multicolumn{3}{|c|}{ Concentration (nmol/L) } \\
\hline Filter-water A & $3.0( \pm 0.2, n=4)$ & & $0.9( \pm 0.1, \mathrm{n}=4)$ \\
\hline Filter-water B & $5.6( \pm 1.4, \mathrm{n}=5)$ & & $0.2( \pm 0.1, \mathrm{n}=5)$ \\
\hline Filtrate-water A & $116.8( \pm 37.0, \mathrm{n}=6)$ & & $57.5( \pm 12.6, \mathrm{n}=7)$ \\
\hline Filtrate-water B & $600.0( \pm 74.0, \mathrm{n}=6)$ & & $423.0( \pm 100.5, \mathrm{n}=6)$ \\
\hline
\end{tabular}

\section{Comparison between $\mathrm{NaClO}$ oxidation and conventional methods}

Iodine concentrations in reaction solutions extracted from reference soils and sediment A via alkaline reagent are shown in Fig 3. Results for seaweed are not shown in this figure because accurate voltammogram was not obtained due to the overlap of unknown peaks. The results from reference soil were $63 \%$ of the measured value obtained under the conditions recommended in section of 'Condition of $\mathrm{NaClO}$ oxidation'. A similar comparison of sediment $A$ also showed lower values; $74 \%$ of the value measured by the present method in this study.

These results suggest that a portion of OI associated with alkaline-insoluble organic matter may not be broken down by the alkaline degradation procedure. Considering the difficulty in obtaining usable voltammogram data, as well as weak degradation ability, alkaline degradation combined with voltammetry is unsuitable for the measurement of total iodine in environmental samples.

Comparison between the present method and the combustion method is shown in Table 3. Concentrations of total iodine in reference soil, sediment A, and seaweed were similar between the methods whereas those in sediment B and natural waters were different. Concentrations obtained by dry combustion showed lower values than those analyzed by the present method, particularly for the filter samples.

Two possibilities can be suggested as reasons for why the lower concentrations were obtained by dry combustion for several samples. The first is an incorporation of the iodine molecule into organic matter; previous studies suggest that iodine reacts rapidly to bind with organic matter in natural environments (Wong, 1982; Francois, 1987). Iodine molecule can be trapped by the structure of organic matter if a significant 
amount of volatile organic matter is produced during combustion. As filter samples analyzed in the present study contained high concentrations of chlorophyll (Table 2), they likely had a high contribution of POC into the whole particle and therefore may have been more affected by the trapping effect during combustion compared to other samples. The second reason why samples obtained via the combustion method might produce lower iodine concentration is the existence of refractory OI. A previous observation on the combustion method study suggested that a portion of environmental organic matter alters to refractory material by polymerization during combustion (Lim and Cachier, 1996). If iodine is incorporated into such polymerized organic matter, then the iodine concentration determined by dry combustion would underestimate the real concentration. Because wet oxidation can avoid polymerization during degradation process (Lim and Cachier, 1996; Cornelissen et al., 2005), the present method is at an advantage for measuring the total iodine concentration more accurately in environmental samples.

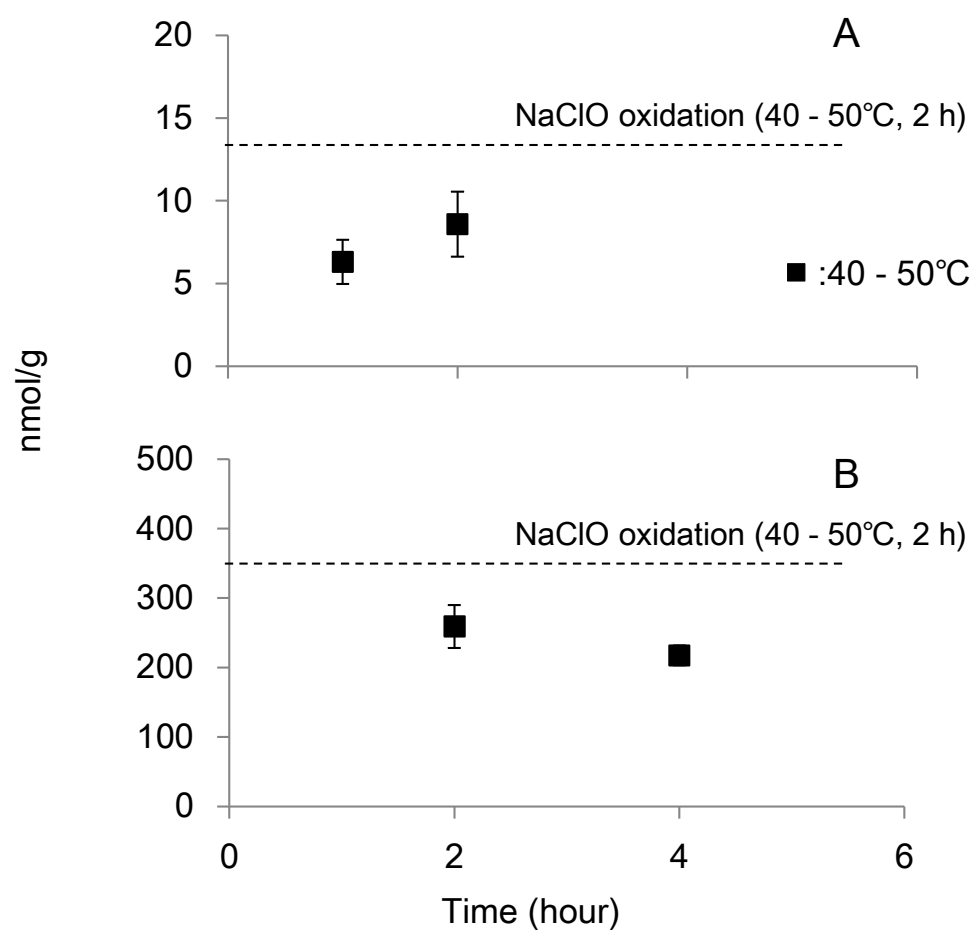

Fig. 3 - Iodine concentrations in a solution processed by alkaline degradation for (A) reference soil and (B) sediment A. Broken lines represent the measurement value of the $\mathrm{NaClO}$ oxidation at $40-50^{\circ} \mathrm{C}$ for $2 \mathrm{~h}$. 


\section{CONCLUSIONS}

We have developed a $\mathrm{NaClO}$ oxidation procedure to measure the total iodine concentration in various environmental samples more accurately. For successful decomposition of $\mathrm{OI}$, the following reaction conditions are recommended: $\mathrm{NaClO}$ concentration, $0.3 \%(\mathrm{w} / \mathrm{w})$; reaction temperature, $40-50^{\circ} \mathrm{C}$; and reaction duration, $2 \mathrm{~h}$.

The present method can be applied to samples containing $\geq 3.2 \mu \mathrm{mol}$ or $\geq 7.3 \mu \mathrm{mol} / \mathrm{g}$ of OI. The recovery yield of iodine obtained by the present method was higher than that by the alkaline degradation method. This result indicates that the present method successfully breaks down the iodine that was incorporated into the alkaline-insoluble fraction. The comparison between the present method and dry combustion method also exhibited higher recovery of iodine. This may be due to the trapping effect by organic matter and the existence of refractory organic matter. The method developed in this study can be applied to various samples, including dissolved as well as particulate forms, in the aquatic environment.

\section{REFERENCES}

Amachi S. (2008) Microbial contribution to global iodine cycling: Volatilization, accumulation, reduction, oxidation, and sorption of iodine. Microbes Environ., 23(4), 269-276.

Becker V. J., Bennett J. H. and Manuel O. K. (1972) Iodine and uranium in sedimentary rocks. Chem. Geol., 9(1-4), 133-136.

Campos M. L. A. M. (1997) New approach to evaluating dissolved iodine speciation in natural waters using cathodic stripping voltammetry and a storage study for preserving iodine species. Mar. Chem., 57(1-2), 107-117.

Chao T. T. and Sanzolone R. F. (1992) Decomposition techniques. J. Geochem. Explor., 44(1-3), 65-106.

Chen Z., Megharaj M. and Naidu R. (2007) Speciation of iodate and iodide in seawater by non-suppressed ion chromatography with inductively coupled plasma mass spectrometry. Talanta, 72(5), 1842-1846.

Cook P. L. M., Carpenter P. D. and Butler E. C. V. (2000) Speciation of dissolved iodine in the waters of a humic-rich estuary. Mar. Chem., 69(3-4), 179-192.

Cornelissen G., Gustafsson O., Bucheli T. D., Jonker M. T. O., Koelmans A. A. and van Noort P. C. M. (2005) Extensive sorption of organic compounds to black carbon, coal, and kerogen in sediments and soils: Mechanisms and consequences for distribution, bioaccumulation, and biodegradation. Environ. Sci. Technol., 39(18), 6881-6895.

Elderfield H. and Truesdale V. W. (1980) On the biophilic nature of iodine in seawater. Earth Planet. Sci. Lett., 50(1), 105-114.

Ertel J. R. and Hedges J. I. (1984) The lignin component of humic substances: Distribution among soil and sedimentary humic, fulvic, and base-insoluble fraction. Geochim. Cosmochim. Acta, 48(10), 2065-2074.

Francois R. (1987) The influence of humic substances on the geochemistry of iodine in nearshore and hemipelagic marine sediments. Geochim. Cosmochim. Acta, 51(9), 2417-2427.

Harada M. and Sakurai K. (1999) K-line X-ray fluorescence analysis of high-Z elements. Spectrochim. Acta B, 54(1), 29-39. 
Harvey G. R. (1980) A study of the chemistry of iodine and bromine in marine sediments. Mar. Chem., 8(4), 327-332.

Hedges J. I. (2002) Why dissolved organics matter? In: Biogeochemistry of Marine Dissolved Organic Matter, Hansell D. A. and Carlson C. A. (eds), Academic Press, San Diego, USA, pp.1-34.

Hou X., Chai C., Qian Q., Yan X. and Fan X. (1997) Determination of chemical species of iodine in some seaweeds (I). Sci. Total Environ., 204(3), 215-221.

Hou X., Hansen V., Aldahan A., Possnert G., Lind O. C. and Lujaniene G. (2009) A review on speciation of iodine-129 in the environmental and biological samples. Anal. Chim. Acta, 632(2), 181-196.

Kupper F. C., Carpenter L. J., McFiggans G. B., Palmer C. J., Waite T. J., Boneberg E., Woitsch S., Weiller M., Abela R., Grolimund D., Potin P., Butler A., Luther III G. W., Kroneck P. M. H., Meyer-Klaucke W. and Feiters M. C. (2008) Iodide accumulation provides kelp with an inorganic antioxidant impacting atmospheric chemistry. PNAS, 105(19), 6954-6958.

Lim B. and Cachier H. (1996) Determination of black carbon by chemical oxidation and thermal treatment in recent marine and lake sediments and Cretaceous-Tertiary clays. Chem. Geol., 131(1-4), 143-154.

Luther III G. W., Ferdelman T., Culberson C. H., Kostka J. and Wu J. (1991) Iodine chemistry in the water column of the Chesapeake Bay: Evidence for organic iodine forms. Estuar. Coast. Shelf Sci., 32(3), 267-279

McKenna J. H. and Doering P. H. (1995) Measurement of dissolved organic carbon by wet chemical oxidation with persulfate: influence of chloride concentration and reagent volume. Mar. Chem., 48(2), 109-114.

Muramatsu Y., Takada Y., Matsuzaki H. and Yoshida S. (2008) AMS analysis of ${ }^{129}$ I in Japanese soil samples collected from background areas far from nuclear facilities. Quat. Geochronol., 3(3), 291-297.

Schnitzer M. and Schuppli P. (1989) The extraction of organic matter from selected soils and particle size fractions with $0.5 \mathrm{M} \mathrm{NaOH}$ and $0.1 \mathrm{M} \mathrm{Na}_{4} \mathrm{P}_{2} \mathrm{O}_{7}$ solutions. Can. J. Soil Sci., 69(2), 253-262.

Stevenson F. J. and Goh K. M. (1971) Infrared spectra of humic acids and related substances. Geochim. Cosmochim. Acta, 35(5), 471-483.

Takayanagi K. and Wong G. T. F. (1986) The oxidation of iodide to iodate for the polarographic determination of total iodine in natural waters. Talanta, 33(5), 451-454.

Truesdale V. W. and Spencer C. P. (1974) Studies on the determination of inorganic iodine in seawater. Mar. Chem., 2(1), 33-47.

Wong G. T. F. (1982) The stability of molecular iodine in seawater. Mar. Chem., 11(1), 91-95.

Wong G. T. F. and Chen X. (1998) Dissolved organic iodine in marine waters: Determination, occurrence and analytical implications. Mar. Chem., 59(3-4), 271-281.

Zhang S., Schwehr K. A., Ho Y., Xu C., Roberts K. A., Kaplan D. I., Brinkmeyer R., Yeager C. M. and Santschi P. H. (2010) A novel approach for the simultaneous determination of iodide, iodate and organo-iodide for ${ }^{127} \mathrm{I}$ and ${ }^{129} \mathrm{I}$ in environmental samples using gas chromatography-mass spectrometry. Environ. Sci. Technol., 44(23), 9042-9048. 